\title{
Los movimientos indígenas de América Latina*
}

\author{
Indian Movements of Latin America
}

\section{Carlos Antonio Aguirre Rojas}

Universidad Nacional Autónoma de México

aguirrec@unam.mx

\section{Resumen}

Este artículo se sitúa en una discusión actual sobre los movimientos indígenas en América Latina a lo largo de los últimos treinta años. Se trata de movimientos sociales que se expresan en ascensos al poder y en reformas orientadas hacia cambios sociales que buscan darle una vuelta al neoliberalismo como sistema económico dominante. Lo antisistémico de los movimientos indígenas, como en el caso de Bolivia, Chile, Ecuador y México, se concentra en una fuerte crítica a los gobiernos de turno y de sus políticas públicas que, en la mayoría de los casos, expresan un claro perfil neodesarrollista y socialdemócrata que tiende hacia lo protocapitalista. Desde la comprensión de los movimientos indígenas, y de su cosmovisión, podemos identificar una profunda critica al proyecto burguéscapitalista-dominante que, gracias a una comprensión profunda del territorio y de su identidad, diseña estrategias de reivindicación a favor de la lucha antisistémica mundial.

Palabras claves: Movimientos indígenas; anticapitalismo; antisistémico; América Latina.

\section{Abstract}

This article is set into the current discussion about Indian movements in Latin America over the past thirty years. The focus lies on social movements which are expressed through the rise to power and reforms tending to social changes that seek a change of neoliberalism as the dominant economic system. The anti-systemic idea

\footnotetext{
* Este artículo se publicó por primera vez la revista china Journal of Latin America Studies, $\mathrm{N}^{\circ} 40$, Vol. 4 (2018), 101-116.
} 
of Indian movements, as in the case of Bolivia, Chile, Ecuador and Mexico, is concentrated into a strong critique of the respective governments and their public policies that, in the majority of the cases, express a clear neoliberal development and a social democratic profile that tends towards proto-capitalism. From the understanding of Indian movements and their worldview we can identify a deep critique of the bourgeois-capitalism-dominant project that, thanks to a deep understanding of the territory and it's identity, designs revindication strategies for the global struggle against the current system.

Keywords: Indian movements; anti-capitalism; anti-systemic; Latin America.

"Son indígenas rebeldes. Rompen así con el esquema tradicional que, primero de parte de Europa, y después de todos aquellos que visten el color del dinero, les fue impuesto para mirar y ser mirados".

Subcomandante Insurgente Marcos, Chiapas, la Treceava Estela, julio de 2003.

\section{La presencia de los movimientos indígenas en la América Latina actual}

Si observamos con cuidado la situación actual de América Latina, en estos inicios del tercer milenio, nos llamará la atención de inmediato, el excepcional dinamismo de su vida política, durante los últimos cinco o seis lustros recién transcurridos. Porque es claro que en el último cuarto de siglo, hemos asistido en Latinoamérica a un vertiginoso y complejo proceso de rápidos cambios sociales y políticos, que incluyen lo mismo virajes importantes desde gobiernos de derecha y hasta ultraderecha hacia gobiernos de izquierda moderada, y a la inversa, desde esos gobiernos llamados 'progresistas' hacia nuevos gobiernos de derecha $y$ antipopulares, que vastas movilizaciones sociales y populares que, con su acción profunda, han logrado incluso derrocar gobiernos nacionales de manera pacífica. Y ello, pasando también por la clara modificación de la agenda política y de la situación política general de la gran mayoría de las naciones latinoamericanas, o por la conformación y consolidación de fuertes movimientos anticapitalistas y antisistémicos, que han sido capaces de crear, en múltiples lugares de nuestro 
semicontinente, espacios y territorios autónomos, ya no regidos por la lógica capitalista, hoy todavía dominante en escala mundial. ${ }^{1}$

$\mathrm{Y}$ es claro que gran parte de ese excepcional dinamismo político de América Latina, se debe a esa proliferación en su seno de vastos y potentes movimientos antisistémicos de nuevo tipo, los que en su conjunto, pueden hoy ser considerados como los movimientos sociales anticapitalistas más avanzados de todo el planeta, es decir, como el frente de vanguardia de la actual lucha antisistémica mundial. Y si alrededor de 1920, la revolución rusa era el frente de vanguardia de las luchas sociales mundiales, funcionando como una suerte de 'modelo' ejemplar para todas las restantes luchas anticapitalistas del globo terráqueo en aquellos tiempos, ahora, casi cien años después, este papel lo ocupan los movimientos anticapitalistas del mundo latinoamericano, los que crearon y han mantenido la iniciativa de los Foros Sociales Mundiales, y que en varias ocasiones han sido capaces de provocar la caída pacifica de sus gobiernos nacionales, al mismo tiempo en que demuestran que pueden movilizar al conjunto de las clases y sectores subalternos de sus países y de paralizar el funcionamiento de sus respectivas sociedades, además de haber comenzado ya a crear, en pequeña y mediana escala, esos mundos no capitalistas antes mencionados. ${ }^{2}$

Y vale la pena subrayar que, dentro del vasto conjunto de esos potentes movimientos anticapitalistas y antisistémicos de América Latina, tienen un papel destacado los movimientos específicamente indígenas, los que habiéndose constituido como movimientos sociales diferentes e independientes de los movimientos campesinos, hace sólo unas pocas décadas, han logrado sin embargo, en este breve periodo de su existencia reciente, ubicarse en un lugar central de las luchas antisistémicas contemporáneas. Lugar central y protagónico dentro de los combates y protestas más recientes, que se hace evidente si revisamos la historia de América Latina en las últimas tres décadas.

\footnotetext{
1 Sobre esta situación actual de América Latina, y sobre sus principales tendencias políticas recientes, cfr. Raúl Zibechi, Autonomías y emancipaciones. América Latina en movimiento, Ed. Quimantú, Santiago de Chile, 2008, y (en coautoría con Decio Machado), Cambiar el mundo desde arriba. Los límites del progresismo, Ed. Desde Abajo, Bogotá, 2016, y Carlos Antonio Aguirre Rojas, L'Amérique Latine en rébellion, Ed. L’Harmattan, Paris, 2008, América Latina. História e Presente, Ed. Papirus, Sao Paulo, 2004, y América Latina: Crisis Global y Cultura Plural, (en idioma chino), Ed. Universidad de Shen Zhen, Shen Zhen, 2005.

2 Sobre estos movimientos sociales anticapitalistas de Latinoamérica, véase Immanuel Wallerstein, Historia y dilemas de los movimientos antisistémicos, Ed. Contrahistorias, México, 2008, Raúl Zibechi, Movimientos Sociales en América Latina. El 'mundo otro' en movimiento, Ed. Desde Abajo, Bogotá, 2017, y Carlos Antonio Aguirre Rojas, Movimenti Antisistemici. Pensare un'alternativa nel XXI secolo, Ed. Aracne Editrice, Roma, 2013, y "Les nouveaux mouvements antisystemiques en Amérique Latine: une brève radiographie générale", en Review, vol. XXXI, núm. 1, 2008.
} 
Por ejemplo, el movimiento indígena mapuche de Chile, el que si bien no es cuantitativamente muy grande, si ha tenido en cambio un rol cualitativo central en la historia chilena reciente. Pues si la población mapuche en Chile representa alrededor del 9\% de la población total, el movimiento mapuche es en cambio un movimiento que desde 1990 y hasta la fecha, ha cuestionado permanentemente a todos los gobiernos chilenos, tanto a los nacidos de la llamada 'concertación' como a los gobiernos de la ultraderecha, demostrando por ejemplo la falsedad del supuesto 'progresismo' del Partido Socialista chileno, y el racismo profundo y excluyente de todos esos gobiernos. Razón por la cual, este movimiento mapuche ha sido también constantemente criminalizado por esos gobiernos, aplicándole absurdas leyes supuestamente antiterroristas, y encarcelando reiteradamente a sus principales líderes sociales. Frente a lo cual, y desde su fracción más radical, la de la Coordinadora Arauco Malleco, ese movimiento indígena mapuche ha defendido durante estas tres décadas, un proyecto radicalmente anticapitalista para la transformación profunda de Chile. ${ }^{3}$

0 también el caso del movimiento indígena ecuatoriano, el que desde 1990 llevó a cabo un levantamiento nacional que paralizó al país entero, y que más adelante participó de manera central en las movilizaciones populares que provocaron la caída de los gobiernos de Abdalá Bucaram en 1997, de Jamil Mahuad en el año 2000 y de Lucio Gutiérrez en 2005. Y es claro que fue la presión y el protagonismo de este movimiento indígena ecuatoriano, concentrado en torno de la CONAIE o Confederación de Nacionalidades Indígenas del Ecuador, el que creó las condiciones para la formación del gobierno de Rafael Correa, el que entre 2007 y 2017 gobernó Ecuador desplegando una retórica supuestamente radical, que incluso llegó a afirmar que en ese país se estaba desarrollando, igual que en Venezuela o en Bolivia, el 'Socialismo del Siglo XXI', lo que más adelante se modificó para plantear, en una línea mucho más moderada pero también más realista, que lo que se desplegaba en Ecuador era más bien una 'Revolución Ciudadana'.

Pero más allá de esta retórica, en los hechos, ese gobierno de Correa fue simplemente un gobierno tenuemente socialdemócrata en lo político, y claramente neokeynesiano y neodesarrollista en lo económico, defendiendo y promoviendo enérgicamente los intereses de la burguesía nacional ecuatoriana. Sin embargo, y en

\footnotetext{
3 Para la cifra de la población mapuche respecto de la población chilena total, tema aún en debate, cfr. el ensayo de Marcos Rodrigo Valdés Castillo, "Tres décadas de cuantificación de la población indígena en Chile a través de los Censos", en Notas de Población, vol. 43, núm. 103, jul-dic de 2016. Sobre la historia de este movimiento mapuche, cfr. Fernando Pairicán, Malon. La rebelión del movimiento mapuche 1990 - 2013, Ed. Pehuén Editores, Santiago de Chile, 2014, y Coordinadora Arauco Malleco, "El pensamiento emancipatorio de la Coordinadora de Comunidades Mapuche en Conflicto (CAM)" en Contrahistorias, núm. 25, 2015.
} 
virtud de la presión de los pueblos indígenas y de la CONAIE, hubo algunas modificaciones importantes como la de reconocer oficialmente a Ecuador como un Estado plurinacional e intercultural, lo que significaba reconocer, al menos en el papel, a las quince nacionalidades indígenas de ese país y a sus respectivas culturas.

Y no es casual el hecho de que, una vez afianzado en el poder, Rafael Correa también se enfrentó a la CONAIE, persiguiendo judicialmente a varios de sus dirigentes, y haciendo burla, en una ocasión, de que los pueblos indígenas de Ecuador eran una pequeña minoría, a pesar de que la población indígena es, según las cifras oficiales, alrededor del 8 o 10\% de la población total ecuatoriana (cifras oficiales que por razones políticas subestiman enormemente la realidad). Frente a lo cual, los sectores más radicales de la CONAIE, hablan de preparar hacia el futuro, ahora en contra del neoliberal gobierno de Lenin Moreno, sumiso a los designios de Estados Unidos, nuevos y más masivos 'levantamientos' indígenas, organizados desde una lógica radicalmente anticapitalista.4

Y sucede algo similar en el caso del movimiento indígena boliviano, el que después de haber protagonizado combates muy importantes, como la guerra del agua del año 2000 y la guerra del gas en el 2003, y de haber provocado con sus movilizaciones pacíficas aunque radicales, la caída de los tres gobiernos de Hugo Bánzer, de Gonzalo Sánchez de Losada y de Carlos Mesa, abrió el espacio para la llegada al poder de Evo Morales, quien utilizando también una retórica de ser, supuestamente, un gobierno anticolonial, progresista y de izquierda, no ha dudado en reprimir a los movimientos indígenas, como sucedió en 2011, en el caso de la oposición indígena al Proyecto del TIPNIS o Territorio Indígena Parque Nacional Isiboro Sécure, el que después de haber sido temporalmente suspendido, luego de la victoria indígena inicial, ha vuelto a ser ahora retomado y relanzado con más fuerza.

\footnotetext{
${ }_{4}^{4}$ Sobre el levantamiento indígena de 1990, cfr. el libro de varios autores, Indios. Una reflexión sobre el levantamiento indígena de 1990, Ed. Abya Yala, Quito, 1992. Sobre el movimiento indígena ecuatoriano, véanse los libros colectivos, de varios autores, Yuyarinakuy. Digamos lo que somos, antes que otros nos den diciendo lo que no somos, Ed. Abya Yala, Quito, 2001, Autonomía Indígena frente al Estado nación y la globalización neoliberal, Ed. Abya Yala, Quito, 2005, y los Boletines, Documentos y materiales publicados por la CONAIE, parte de ellos consultables en su sitio de internet: https://www.conaie.org, además de Marlon Santi, "Un nuevo giro hacia la izquierda. La Confederación de Nacionalidades Indígenas del Ecuador. Entrevista" en Contrahistorias, núm. 11, 2008. Para la caracterización del gobierno de Rafael Correa, y más en general de los llamados gobiernos 'progresistas' de América Latina, cfr. Bolívar Echeverría, "El Socialismo del Siglo XXI es un Capitalismo Cristiano Corregido", en Contrahistorias, núm. 16, México, 2011, Subcomandante Insurgente Marcos, "De redentores e irredentos", discurso del 16 de julio de 2007, en el sitio de 'Enlace Zapatista', http://www.ezln.org.mx, y la entrevista "El elemento extra: la organización", en Rebeldía, núm. 42, 2006, Raúl Zibechi, "Crítica de los gobiernos "progresistas"”, en Contrahistorias, núm. 26, México, 2016, y Carlos Antonio Aguirre Rojas, Antimanuale del buon ribelle, Ed. Aracne Editrice, Roma, 2015, especialmente el capítulo 3, y "Lateinamerika heute: Eine Darstellung aus der Sicht den 'langen Dauer"', en Comparativ, año 12, núm. 5/6, 2002.
} 
Y también, el gobierno de Evo Morales ha reprimido a los movimientos sociales radicales que, en ciertas coyunturas, han criticado a su gobierno y se han opuesto a sus políticas, igualmente neodesarrollistas y socialdemócratas, pero totalmente procapitalistas, las que en los hechos sólo benefician a la burguesía nacional boliviana, mucho más que a los sectores populares de esa nación sudamericana. 5

Y si una parte de ese movimiento indígena boliviano, se ha dejado cooptar hasta ahora por este gobierno moderado y procapitalista de Evo Morales, gobierno que ahora y en contra de la propia ley boliviana, quiere eternizarse en el poder haciéndose reelegir nuevamente en este año de 2019, en cambio sus sectores más radicales, como el movimiento Pachakuti de Felipe Quispe, o los sectores más de izquierda del movimiento indígena de la ciudad de El Alto, continúan organizándose y luchando, para defender aún un proyecto genuinamente anticapitalista y antisistémico. 6

También muy importante, en los últimos cinco lustros, ha sido el papel del movimiento indígena rebelde del neozapatismo, dentro de México, pero también dentro de toda América Latina, e incluso dentro del mundo entero. Porque después del 1 de enero de 1994, y de su radical irrupción dentro del escenario político mexicano, este neozapatismo se ha convertido rápidamente y hasta la actualidad, en un referente modélico y ejemplar para prácticamente todas las luchas antisistémicas del Planeta Tierra. Y ello, no sólo por haber revertido a nivel mundial, los efectos negativos y paralizantes de la caída del Muro de Berlín y del colapso definitivo de las diversas experiencias del llamado 'Socialismo Real' del siglo XX, sino también por haber cambiado de manera radical la situación de todos los pueblos indígenas de Latinoamérica, a los que les devolvió la confianza en sí mismos, y la conciencia de sus fuerzas y de sus potencialidades actuales y futuras.

Porque al darle voz en México, a esos siempre olvidados, marginados e invisibilizados pueblos indios, situándolos además en el centro del drama histórico,

\footnotetext{
5 Sobre el movimiento indígena de oposición al Proyecto del TIPNIS, cfr. el libro colectivo La victoria indígena del TIPNIS, Ed. Imprenta WA-GUI, La Paz, 2012. Y sobre la crítica de los movimientos sociales a las políticas procapitalistas del gobierno del MAS de Evo Morales, cfr. Oscar Olivera y otros, "Carta Pública Abierta a Evo Morales y a Álvaro García, contra el Gasolinazo y por el Autogobierno de nuestro pueblo", en Contrahistorias, núm. 16, 2011.

6 Para profundizar un poco más en esta historia reciente del movimiento indígena boliviano, y en especial su sector más anticapitalista, cfr. Oscar Olivera y otros, Nosotros somos la Coordinadora, Ed. Fundación Abril, La Paz, 2008, Luis A. Gómez, El Alto de Pie. Una insurrección aymara en Bolivia, Ed. Imprenta Wa-Gui, La Paz, 2006, Felipe Quispe, La caída de Goni, Ed. Pachakuti, La Paz, 2013, y "Entrevista sobre la situación actual de Bolivia (23 de junio de 2015)", en Contrahistorias, núm. 26, 2016, y Carlos Antonio Aguirre Rojas, "Bolivia rebelde. Las lecciones de los sucesos de mayo y junio de 2005, en perspectiva histórica", en Contrahistorias, núm. 5, 2005. También vale la pena consultar los siete números de la revista Willka. Análisis, pensamiento y acción de los pueblos en lucha, publicados entre 2007 y 2013.
} 
ese neozapatismo mexicano abrió el espacio que hizo posible, en toda América Latina, que esos indígenas pasaran desde una posición defensiva y marginal, a una nueva postura ahora ofensiva y central. Lo que a su vez, les permitió mostrar el hecho hasta entonces no demasiado claro, de que lo que ellos representan en el fondo es una versión diferente de desarrollo de la modernidad, un camino distinto de modernización, que en las condiciones actuales, de la crisis terminal del capitalismo, se constituye incluso en la retadora propuesta de una modernidad alternativa, no capitalista, de desarrollo y evolución para toda la humanidad.7

Y esto, por no mencionar a los movimientos indígenas de Perú, Colombia o Guatemala, los que con distinto grado de organización y de maduración, han sido también factores importantes en el decurso político y social reciente de sus respectivos países.

A partir de estos ejemplos mencionados, es fácil reconocer el papel cada vez más protagónico y fundamental de estos movimientos indígenas rebeldes latinoamericanos, dentro de la definición del actual mapa político de la América Latina contemporánea. Pero si esta centralidad es evidente, no lo son tanto las múltiples razones que la explican. Porque durante casi cinco siglos, todas las naciones latinoamericanas mantuvieron a sus respectivas poblaciones indígenas, en un claro estado de marginación y de invisibilización, negándoles el reconocimiento de su identidad indígena y de sus particulares cosmovisiones, lenguajes, hábitos, usos y costumbres y rasgos civilizatorios singulares, pero incluso, en ocasiones, hasta de sus derechos sociales, económicos o políticos más elementales, como su derecho a sus tierras, a sus bosques, a sus aguas y a sus diversos recursos naturales, junto a sus derechos ciudadanos y hasta sus derechos humanos en general.

Pero esto cambió radicalmente en las últimas tres décadas, lo que nos lleva a preguntarnos acerca de las posibles razones generales de este profundo cambio. Revisemos, a modo de simples hipótesis posibles, algunas de esas razones.

\footnotetext{
7 Sobre la importancia mundial de este neozapatismo, cfr. Immanuel Wallerstein, "Capítulo 5. Cuatro acercamientos al neozapatismo mexicano", en su libro Historia y dilemas de los movimientos antisistémicos, ya citado, y "Entrevista sobre los nuevos movimientos antisistémicos en México y en el mundo (enero de 2015)", en Contrahistorias, núm. 24, México, 2015. Véanse también todos los Comunicados de este movimiento en su sitio en internet: http:www.ezln.org.mx, y Carlos Antonio Aguirre Rojas, Gehorchend befehlen. Die politischen Lektionen des mexikanischen Neozapatismus, Ed. Assemblage, Münster, 2013, Chiapas, Planeta Tierra, Ed. Contrahistorias, México, 2010, La tierna furia. Nuevos ensayos sobre el neozapatismo mexicano, Ed. Contrahistorias, México, 2019, y "El significado del neozapatismo mexicano dentro de los movimientos antisistémicos actuales", en Contrahistorias, núm. 22, 2014.
} 


\section{El contexto latinoamericano reciente y los movimientos indígenas.}

$\mathrm{Si}$ analizamos con mirada larga, es decir, desde las vastas perspectivas de la larga duración histórica,8 el papel que ha jugado América Latina dentro de la dinámica global del capitalismo mundial, en los cinco siglos de existencia de este último, podremos comprobar fácilmente que el subcontinente latinoamericano ha sido central para esa dinámica capitalista planetaria, en tres momentos específicos: primero, en el siglo XVI, acompañando el nacimiento mismo del capitalismo en Europa, después a finales del siglo XVIII e inicios del siglo XIX, en torno de los procesos de las Independencias de toda Latinoamérica, y finalmente en estos finales del siglo XX y comienzos del siglo XXI. Y en los tres casos, lógicamente, por razones esencialmente económicas.

Pues como lo han explicado ya los historiadores, el flujo de metales preciosos y de mercancías provenientes de América Latina, en el siglo XVI, fue fundamental para permitir, tanto la monetarización generalizada de las relaciones económicas en toda Europa, como también el aumento de la medida de la riqueza material disponible (como capital comercial, o como crecimiento de los mercados, etc.), para consumar con éxito la transición del feudalismo al capitalismo en esa misma Europa. E igualmente sucedió a finales del siglo XVIII, cuando, como dice Fernand Braudel (1991), Latinoamérica era 'el tesoro del mundo', por sus materias primas, sus metales, y sus múltiples nuevos productos, y cuando nadie, excepto la propia España decadente y cada vez más débil, estaba interesado en que ese tesoro permaneciese en las manos de la nación ibérica. Lo que naturalmente, provocó los vastos procesos de las Independencias latinoamericanas de inicios del siglo XIX.9

Y lo mismo sucede en las últimas tres o cuatro décadas recién vividas, cuando nuestro semicontinente alberga el $80 \%$ de los recursos bióticos de todo el planeta, es decir, las especies animales, pero sobre todo vegetales, que en el inmediato futuro, serán la base de los nuevos desarrollos de las industrias farmacéutica, textil, química, y alimenticia de las generaciones por venir. Y eso, además de los vastos yacimientos de metales viejos y nuevos, como el oro y la plata, pero también el litio o el uranio, de la abundante agua, del viento, y de los bosques, selvas y espacios

\footnotetext{
8 Véase también Carlos Antonio Aguirre Rojas, Fernand Braudel et les sciences humaines, Ed. L'Harmattan, París, 2004, y "A longa duraçao: in illo tempore et nunc", en Revista de Historia Das Ideias, núm. 18, Coimbra, 1996.

9 Sobre estos temas, mencionemos solamente las obras de Fernand Braudel, El Mediterráneo y el mundo mediterráneo en la época de Felipe II, Ed. Fondo de Cultura Económica, México, 2010, y Civilización material, economía y capitalismo. Siglos XV-XVIII, Ed. Alianza Editorial, Madrid, 1984, y de Immanuel Wallerstein, El moderno sistema mundial, tomos I, II, III, y IV, Ed. Siglo XXI, México, 20112014, y Carlos Antonio Aguirre Rojas, "A história da civilizaçao latino-americana", en el libro colectivo Fernand Braudel. Tempo e história, Ed. FGV Editora, Rio de Janeiro, 2003.
} 
ricos y pródigos en todo tipo de recursos naturales. Lo que hace que Latinoamérica vuelva a ser ahora, nuevamente, un 'tesoro del mundo' apetecible y disputado por las principales economías capitalistas hegemónicas de todo el planeta.

Entonces, si tomamos en cuenta que una gran parte de esa nueva riqueza hoy codiciada por los países capitalistas centrales y hegemónicos, está asentada en territorios precisamente indígenas, comprenderemos que, al ser ellos las principales víctimas de los ataques, despojos y robos reiterados, y crecientes de las trasnacionales capitalistas, insaciables y depredadoras, se hayan visto obligados a defenderse y a organizarse, gestando los potentes movimientos indígenas que ya hemos mencionado, los que han ido volviéndose muy visibles y protagónicos, a partir de esos vitales combates en defensa de sus propios territorios y recursos naturales de todo orden. 10

Además, y en virtud de esa enorme riqueza económica potencial, es que América Latina ha adquirido también, en los últimos seis o siete lustros, una significativa presencia planetaria que no había tenido durante casi doscientos años, y que se refleja lo mismo en la difusión mundial de la literatura producida por los autores del llamado 'boom latinoamericano', que en el reconocimiento y adopción del español como lengua de trabajo oficial de la ONU, pero también en la mayor atención de los medios de comunicación de todos los países, respecto de las noticias concernientes a nuestro semicontinente, o en la proliferación de Departamentos de Estudio, Cátedras, Especializaciones, Maestrías y Doctorados consagrados al tema de los Estudios Latinoamericanos, en prácticamente todas las grandes Universidades del mundo. Presencia planetaria acrecentada, que de manera indirecta influye también en la mayor visibilidad mundial y reconocido protagonismo de los movimientos indígenas rebeldes latinoamericanos, los que ahora son mejor conocidos y reconocidos en todo el globo terráqueo.

También, y junto a esta riqueza biótica excepcional, y a la concomitante centralidad mayor de Latinoamérica en las últimas décadas, hay que agregar la situación que ahora vive el capitalismo mundial, y que según Immanuel Wallerstein (2016), es la de la etapa de su crisis estructural o definitiva. Crisis terminal del capitalismo, iniciada desde 1968/1973, y desplegada hasta el día de hoy, que no sólo

\footnotetext{
10 Sobre la riqueza biótica excepcional de América Latina, cfr. el artículo de Alejandro Toledo Ocampo, "Hacia una economía política de la biodiversidad y de los movimientos ecológicos comunitarios", en Chiapas, núm. 6, México, 1998, en donde el autor afirma enfáticamente: "América Latina es la región que concentra la más rica de las biodiversidades del planeta” (p.16). Véase también Joaquín Giménez Heau, "El ISBG: laboratorio global o negocio redondo", en Chiapas, núm. 12, México, 2001. Y sobre el dato, planteado por la Organización Internacional del Trabajo, de que esos nuevos recursos bióticos se encuentran en un $60 \%$ en territorios indígenas, cfr. Subcomandante Insurgente Marcos, "Siete piezas sueltas del rompecabezas mundial", en Escritos sobre la guerra y la economía política, Ed. Pensamiento Crítico Ediciones, México, 2017, p. 107.
} 
anuncia el cercano fin histórico de este destructivo y terrible sistema capitalista, es decir, del modo de producción capitalista y de la entera sociedad burguesa que sobre él se construye, sino también y junto con todo esto, el final simultáneo de todas las estructuras características de las sociedades divididas en clases sociales, y entre ellas, la familia patriarcal y el machismo, o también la antítesis entre el campo y la ciudad, o igualmente la división entre el trabajo manual y el trabajo intelectual, igual que la muerte del arte o de la ciencia, concebidos como actividades exclusivas de un pequeño sector específico de la sociedad.11

Y junto con todo esto, también el final del racismo y de la discriminación racial de unos seres humanos hacia otros. Porque uno de los procesos que impulsa el capitalismo, en su insaciable sed de mercados y de plusvalor, es el de la formación del mercado mundial capitalista, el que constituye el esqueleto material y la base real de la universalización histórica de la humanidad, y con ello, del nacimiento de la verdadera historia universal. Pero gracias a esta universalización de la historia, todos los pueblos, grupos humanos y civilizaciones del planeta han terminado por conocerse y reconocerse ampliamente, lo que lenta pero progresivamente, va minando ese 'miedo al otro' y ese 'temor al diferente' que está en la base del racismo en general, y del racismo capitalista en particular.12

Entonces, con la crisis terminal del capitalismo, y gracias a esa universalización histórica alcanzada, entra en crisis también el racismo, capitalista y en general, lo que permite entre muchos otros síntomas, reconocer también a los pueblos indígenas de América Latina como actores sociales específicos, fundamentales, e igualmente importantes de sus respectivas sociedades. Y con ello, abre el espacio para la nueva legitimidad y centralidad de los movimientos indígenas que esos pueblos indios latinoamericanos han gestado en estos últimos lustros.

\footnotetext{
11 Sobre esta crisis terminal del capitalismo, cfr. Immanuel Wallerstein, La crisis estructural del capitalismo, Ed. Quimantú, Santiago de Chile, 2016, Después del liberalismo, Ed. Siglo XXI, México, 1996, y Horizontes del análisis del sistema-mundo moderno, Ed. Instituto Politécnico Nacional, México, 2015, Carlos Antonio Aguirre Rojas, Para compreender o século XXI. Uma gramática de longa duração, Ed. Universidade de Passo Fundo - Editora da Pontificia Universidade Catolica de Rio Grande do Sul, Porto Alegre, 2010, y “'Globalization' and 'Mondialization': A Critical - Historical Perspective”, en Stiinte Politice, tomo 2, Iasi, Rumania, 2007, y también Immanuel Wallerstein, Charles Lemert y Carlos Antonio Aguirre Rojas, Uncertain Worlds. World-Systems Analysis in Changing Times, Ed. Paradigm Publishers, Bouldon, 2012.

12 Sobre la universalización histórica, y el nacimiento de la historia universal, ambos obra del capitalismo, cfr. Carlos Marx y Federico Engels, Manifiesto del Partido Comunista, Ed. en Lenguas Extranjeras, Pekín, 1973. Y sobre el racismo y sus fundamentos más profundos, cfr. Immanuel Wallerstein y Etienne, Balibar, Race, Nation, Class. Ambiguous Identities, Ed. Verso, Londres y Nueva York, 2005, y Norbert Elías, Establecidos y marginales, Ed. Fondo de Cultura Económica, México, 2016, y Compromiso y distanciamiento, Ed. Península, Barcelona, 1990.
} 
De otra parte, junto al colapso terminal del capitalismo mundial, vemos ahora colapsar también, en todo el planeta, las artificiales estructuras nacionales que ese mismo capitalismo creó, y que durante sólo algunos pocos siglos, sirvieron como forma de agrupación y organización de las sociedades y de los grupos humanos en general. Pero no debemos olvidar que, al instaurarse, siempre por la fuerza y de manera violenta, las distintas naciones del mundo tendieron a marginar, negar e invisibilizar, a las diversas identidades locales, civilizatorias y concretas de cada grupo humano, subsumiéndolas en la absurda condición homogeneizante de ser todos 'ciudadanos' de tal o cual país en particular. Y entre estas identidades negadas e invisibilizadas, estuvo también, en varios países de América Latina, la identidad de sus pueblos indios, la que fue simplemente ignorada, cuando no, a veces, abiertamente reprimida y estigmatizada.

Sin embargo, y al entrar también en su crisis terminal esas estructuras nacionales capitalistas, se abre el espacio para la reemergencia y nueva afirmación de esas identidades antes reprimidas y negadas, lo que entre muchos otros factores, también redunda en la reciente reafirmación y protagonismo de los movimientos indios de toda América Latina. ${ }^{3}$

Otro fenómeno importante que ha influido en el nuevo papel, mucho más relevante y fundamental, que hoy tienen los movimientos indígenas de toda Latinoamérica, es la radical reconfiguración que los movimientos sociales de protesta y de oposición al capitalismo han vivido en las últimas cinco décadas, y que se explica también por el nuevo contexto de la entrada en la etapa de la crisis terminal del capitalismo mundial. Pues si antes de 1968-1973, se afirmaba que la clase obrera industrial era el único agente o sujeto revolucionario, o por lo menos el principal y fundamental, en cambio después de esa fecha, se ha comenzado a reconocer la gran pluralidad y diversidad de los distintos sujetos y agentes revolucionarios, entre los que ahora se incluyen a los estudiantes, a las mujeres, a los pobres urbanos, a los campesinos, a los desocupados, a los sin tierra, a los migrantes, etc., así como a una gran diversidad de las llamadas 'minorías'. Y junto a todos ellos, naturalmente también a los pueblos indígenas de todo el planeta, y también de América Latina.

\footnotetext{
13 Todavía se discute sobre la fecha de origen de esas estructuras nacionales, pero se coincide en identificarlas como una creación del capitalismo. Al respecto, y para ver las muy diversas evaluaciones de este fenómeno de la estructura del Estado-Nación, cfr. Norbert Elías, El proceso de la civilización, Ed. Fondo de Cultura Económica, México, 1989, Benedict Anderson, Comunidades imaginadas. Reflexiones sobre el origen y la difusión del nacionalismo, Ed. Fondo de Cultura Económica, México, 1993, Eric Hobsbawm, Naciones y nacionalismo desde 1780, Ed. Crítica, Barcelona, 1991 y Michel Foucault, Seguridad, Territorio, Población, Ed. Fondo de Cultura Económica, Buenos Aires, 2006. Y sobre este nuevo protagonismo reciente de los pueblos indios latinoamericanos, cfr. Carlos Antonio Aguirre Rojas, Movimientos Antisistémicos y Cuestión Indígena en América Latina. Una visión desde la larga duración histórica, Ed. Quimantú, Santiago de Chile, 2018.
} 
Porque si el capitalismo no es solamente el modo de producción burgués, junto a su Estado capitalista despótico y represor, sino también todo una entera sociedad burguesa, y hasta un proyecto de civilización capitalista global, entonces la lucha en su contra y el proceso de su verdadera destrucción y superación radicales tiene que ser obra de la acción múltiple, combinada y diversa de también muchos y muy diferentes clases, sectores, grupos y actores sociales de todo tipo, algo que ha venido a imponerse como evidencia cada vez más, en esta fase terminal del capitalismo mundial. Nueva pluralidad de sujetos anticapitalistas, en donde la clase obrera sigue siendo esencial y primordial, pero donde ahora figuran también, en un lugar destacado, estos movimientos indígenas anticapitalistas y antisistémicos de toda América Latina. 14

Y si los sujetos revolucionarios se multiplican y diversifican, así también se pluralizan y reproducen las demandas de esos nuevos movimientos anticapitalistas en general, agregando entonces a las viejas demandas económicas y políticas, nuevas demandas de orden social, y cultural, e incluso ecológicas, y hasta civilizatorias de todo tipo. Y entre ellas, naturalmente, las demandas indígenas de los pueblos igualmente indios de nuestro semicontinente, demandas como la del respeto y reconocimiento de su identidad cultural propia, o de la aceptación y asunción real del hecho de que esos pueblos indígenas representan, en el fondo, todo un proyecto de civilización moderna diverso del proyecto burgués-capitalista dominante, desde el cual han sido capaces de desarrollar, en las últimas décadas, una real modernidad alternativa a la modernidad capitalista. Una modernidad diferente, antes de resistencia y ahora retadoramente alternativa, que hasta hoy nunca ha sido dominante, sino siempre subordinada, afirmándose desde códigos y principios radicalmente distintos a los códigos dominantes del proyecto europeo occidental capitalista.

Estos son, brevemente apuntados, algunos de los procesos principales que, en nuestra opinión, han influido para modificar la situación y el papel que hoy tienen los pueblos indígenas de América Latina, y junto a ellos, los movimientos indígenas antisistémicos que esos mismos pueblos han construido en los lustros más recientes.

\footnotetext{
14 Sobre esta nueva configuración de los movimientos anticapitalistas actuales, cfr. Immanuel Wallerstein, "Las nuevas rebeliones antisistémicas: ¿un movimiento de movimientos?", en Contrahistorias, núm. 1, 2003, Immanuel Wallerstein, Giovanni Arrighi y Terence Hopkins, Movimientos Antisistémicos, Ed. Akal, Madrid, 1999, Raúl Zibechi, Dibujando fuera de los márgenes. Los movimientos sociales en América Latina. Entrevista, Ed. La Crujía Ediciones, Buenos Aires, 2008, y Carlos Antonio Aguirre Rojas, "O que são os movimentos antisistêmicos?", en História em reflexão, vol. 7, núm. 13, 2013, en:

http://www.periodicos.ufgd.edu.br/index.php/historiaemreflexao, y también Movimenti Antisistemici. Pensare un'alternativa nel XXI Secolo, y Antimanuale del buon ribelle, antes ya citados.
} 
Veamos ahora algunos de los aportes más importantes de esos movimientos a la lucha anticapitalista mundial, hoy todavía en curso.

\section{Algunos aportes de los movimientos indígenas latinoamericanos a la lucha antisistémica mundial}

Dada esta nueva centralidad y protagonismo que han adquirido los movimientos indígenas rebeldes de Latinoamérica en los últimos lustros, es importante preguntarnos acerca de qué es lo que ellos pueden aportar, como su contribución específica, al más vasto conjunto de las luchas anticapitalistas que hoy se despliegan en todo el planeta Tierra. Y al observar con cuidado las demandas, las reivindicaciones y los logros teóricos y prácticos que estos movimientos han ido concretando en estos años recientes, resulta evidente que esta contribución deriva, en una medida importante, de lo que representan hoy esos pueblos indios latinoamericanos, dentro de sus respectivas sociedades nacionales. Y eso que ellos representan, es claramente fruto de la singular historia que ellos han vivido, desde la Conquista española y hasta la actualidad.

Pues al observar con cuidado la historia de estos pueblos indígenas, resulta claro que, en términos generales, la conquista española y portuguesa fue una empresa solo a medias exitosa. Lo que, por lo demás, es un rasgo más general de la historia de la expansión capitalista europea en todo el globo, rasgo que se repite por ejemplo en el caso de China, en donde el dominio europeo nunca pudo pasar de las zonas costeras de ese inmenso país, o en el caso de la propia India, que a pesar de doscientos años de ocupación y dominio inglés no perdió nunca el conjunto más esencial de su fisonomía histórica singular. 0 también el caso de muchos países de África, sometidos a potencias europeas y colonizados por décadas, pero que mantienen aún muchos de sus trazos civilizatorios antiguos.

Y sucede lo mismo en América Latina, en donde es claro que vastos grupos de indígenas, si bien fueron sometidos militarmente, y a partir de eso, también expropiados de sus territorios, explotados económicamente, y dominados social y políticamente, sin embargo y a pesar de todo esto, lograron mantener vivos y activos, una parte muy significativa de su cosmovisión del mundo, toda una serie de rasgos culturales centrales, muchas prácticas cotidianas importantes de tipo económico, social, político y cultural, y hasta varios trazos civilizatorios, característicos de su ser indígena más profundo.

Lo que, naturalmente, no significa que su historia se haya detenido y 'congelado' en el momento de la conquista, sino más bien que desde todos esos elementos señalados, esos pueblos indígenas latinoamericanos lograron desplegar 
un camino de modernización diferente al camino de la modernidad capitalista dominante, impuesto por los conquistadores españoles. Es decir, que frente al proyecto dominante de la modernidad capitalista occidental, fruto del mestizaje cultural derivado de esa conquista, los pueblos indios lograron construir y desarrollar, durante cinco siglos y hasta hoy, un proyecto de modernidad distinto, marginal y dominado, que a la vez que hacía posible que esas poblaciones indígenas se modernizaran y se integraran a los procesos generales de la modernidad, les permitía sin embargo reproducir y mantener esos elementos singulares mencionados, desde los cuales se alimentó durante siglos, la persistente y tenaz rebeldía india frente a esa modernidad dominante, y frente al capitalismo que le era subyacente. 15

Proyecto de una modernidad muy diferente a la modernidad capitalista occidental dominante, que además de definir actualmente los singulares perfiles de los movimientos indígenas de América Latina, es también la base nutricia de esa contribución particular de dichos movimientos a la lucha anticapitalista y antisistémica mundial contemporánea.

Por ejemplo, la lucha indígena por la reconquista y defensa de la tierra y del territorio. Una lucha que, a partir de la incorporación de los movimientos indígenas, dejo de ser la antigua lucha por la reforma agraria, o por la devolución o el otorgamiento de la tierra a los campesinos, para convertirse en una nueva lucha, mucho más radical y anticapitalista, por la desmercantificación $y$ desinstrumentalización absolutas de la tierra y del territorio, y por la instauración de una relación totalmente diferente, más armónica, dialógica y respetuosa, con la naturaleza en general. Porque si analizamos la noción capitalista hoy dominante de la naturaleza y de la tierra, que concibe a éstas como algo muerto e inerte, y como instrumentos y materias inferiores al hombre y sólo susceptibles de ser dominadas, controladas y subyugadas por ese mismo hombre (considerado, ridículamente, como 'amo y señor de la naturaleza'), y la comparamos con la rica y compleja noción de la 'Madre Tierra' que defienden y reivindican hoy todos los pueblos indígenas de América Latina, y que concibe a la tierra, al territorio y a la naturaleza como algo vivo y activo, y a la vez como la verdadera 'fuente de la vida', es decir, como el

\footnotetext{
15 Sobre la idea de que en el capitalismo pueden desarrollarse no sólo una, sino varias, diversas variantes de la modernidad, cfr. Bolívar Echeverría, "Modernidad y Capitalismo (15 tesis)", en Las ilusiones de la modernidad, Coedición Ed. UNAM - Ed. El Equilibrista, México, 1995. Sobre la modernidad capitalista dominante en Latinoamérica, cfr. Bolívar Echeverría, La modernidad de lo barroco, Ed. Era, México, 1998. Y sobre el proyecto de una modernidad alternativa y anticapitalista indígena, ejemplificado en el caso específico del neozapatismo mexicano, cfr. Carlos Antonio Aguirre Rojas, Gehorchend befehlen. Die politischen Lektionen des mexikanischen Neozapatismus, y La tierna furia. Nuevos ensayos sobre el neozapatismo mexicano, ambos ya citados.
} 
origen de los colores, de los números, de las leyendas e historias, pero también de los alimentos, del hábitat, de las medicinas, de las construcciones y de la vida en general de toda la humanidad, podremos darnos cuenta de la riqueza de esta contribución de los movimientos indígenas latinoamericanos a la actual lucha anticapitalista mundial. 16

Pues si esa noción capitalista instrumental de la naturaleza, nos ha llevado ya al borde de la catástrofe ecológica que hoy amenaza a la humanidad entera, entonces urge modificar radicalmente nuestra relación y metabolismo actuales con la naturaleza, eliminando la actitud de oposición y confrontación con ella, y sustituyéndola por una nueva postura armónica de respeto, diálogo e interpenetración entre hombre y mundo natural. Lo que es precisamente la lógica de esa defensa de la Madre Tierra que los movimientos indios hacen, cuando claman que ¡La tierra no se compra ni se vende, se ama y se defiende!

También y directamente conectada con esta rica visión de la naturaleza como Madre Tierra, está la noción del 'Buen Vivir', igualmente enarbolada por los movimientos indígenas del semicontinente latinoamericano, frente a la absurda lógica capitalista aún dominante del 'progreso' económico, del crecimiento material desmesurado y de la acumulación sin fin de más y más productos, lógica que en realidad responde a la también infinita e incesable vocación de la acumulación capitalista, derivada de la insaciable lógica de la valorización del valor.

Entonces, mientras que el capitalismo, sumido en esa lógica del crecimiento ilimitado y del desarrollo material acrecentado, nos ha llevado ya al agotamiento de muchos de los recursos naturales, y a la vez, a la absurda y paradójica situación en la que se destruyen y eliminan mercancías ya producidas para que no baje su precio, al mismo tiempo en que se vive escasez, y hambre y miseria, en muchas sociedades del planeta, en cambio los pueblos y los movimientos indios actuales, reivindican esa noción del 'buen vivir', que postula que el hombre debe producir sólo aquella cantidad de riqueza necesaria para poder estar él mismo satisfecho, a partir de

\footnotetext{
16 Esta idea de la tierra como 'Madre Tierra', aún muy vigente en los pueblos y en los movimientos indígenas anticapitalistas de América Latina, es en realidad una idea que todas las sociedades humanas desarrollaron y mantuvieron en alguna etapa de su desarrollo, lo que puede comprobarse leyendo el texto de Mircea Eliade, Tratado de Historia de las Religiones, Ed. Era, México, 2004, especialmente los capítulos VII, VIII y IX. Sobre el punto de la compleja concepción indígena de la Madre Tierra, cfr. Subcomandante Insurgente Moisés, "Economía Política I. Una mirada desde las comunidades zapatistas", y "Economía Política II. Una mirada desde las comunidades zapatistas", ambos incluidos en el libro El pensamiento crítico frente a la hidra capitalista I. Participación de la Comisión Sexta del EZLN, Ed. EZLN, México, 2015, y Carlos Antonio Aguirre Rojas, "Latin America's Antisystemic Movements and its Struggle for the Land in the Twenty-First Century", en Review, vol. XXXIII, núm. 4, 2010.
} 
mantener una relación armónica tanto con la Madre Tierra, como también con todos los demás seres humanos que lo circundan. ${ }^{17}$

Una lógica no cuantitativa sino cualitativa del crecimiento económico y de la producción material, que es además una lógica que entremezcla, creativa y adecuadamente, lo económico con lo ecológico, y con lo social y lo cultural, y que ha sido degradada y banalizada por los gobiernos llamados 'progresistas' de Ecuador y de Bolivia, los que al incluir en sus respectivas Constituciones este principio del 'Buen Vivir', lo han caricaturizado y rebajado, para equipararlo a la ya mencionada noción capitalista de crecimiento y desarrollo económico, o para identificarlo con las definiciones tradicionales de los derechos sociales a la educación, el trabajo, la salud, etc., los que en realidad son su verdadera antípoda.

Si observamos entonces estas dos perspectivas críticas, aportadas por los movimientos indígenas latinoamericanos, la de la idea de la 'Madre Tierra' y la del 'Buen Vivir', veremos que desde ambas se hace posible potenciar y complejizar una parte de las demandas económicas tradicionales de los antiguos movimientos anticapitalistas. Pues en las condiciones actuales, ya no se trata solamente de reivindicar la expropiación de los medios de producción sociales, incluida la tierra, o de proponer en abstracto la construcción de una nueva economía, no capitalista y no regida por la lógica del lucro y de la valorización del valor, sino que ahora es posible plantear ya de una manera más concreta y práctica, la transformación real de la relación esencial entre la humanidad y la naturaleza, en la vía de su asunción como fuente primigenia y fundamental de nuestra vida en general, lo mismo que la construcción de una economía regida por una lógica cualitativa de cuidado del equilibrio entre mundo humano y mundo natural, y de armonía entre ambos, así como de armonía entre los propios seres humanos. Es decir, una recuperación consciente, rica y diversa de nuestra Madre Tierra Naturaleza, y del Buen Vivir cualitativo hacia la comunidad y hacia el mundo natural circundante.

Otro posible aporte importante de los movimientos indígenas que estamos analizando, es el de su concepción sobre la relación entre el yo y el nosotros, es decir, entre el individuo y la comunidad de la que forma parte. Y en este punto, y una vez más alejándose enormemente del individualismo posesivo capitalista prevaleciente, los pueblos y los movimientos indios reivindican una concepción 'nóstrica', en la que el 'nosotros' es siempre más importante que el 'yo', y en donde

17 Sobre el debate actual en torno a las nociones capitalistas de progreso, o crecimiento, o desarrollo, cfr. el libro colectivo, ¿A dónde vamos? Progreso en diferentes culturas, Ed. Fundación PIEB, La Paz, 2004. Y sobre la banalización del concepto del 'buen vivir' en las Constituciones actualmente vigentes de Ecuador y Bolivia, cfr.

www.asambleanacional.gov.ec/documentos/constitucion_de_bolsillo.pdf, https://bolivia.infoleyes.com/norma/469/constitución-política-del-estado-cpe. 
el bienestar y la afirmación de los individuos, no puede ni debe darse nunca en oposición o en contradicción, o incluso en simple detrimento de la comunidad y de los intereses comunitarios en general.

Lo que no quiere decir que el desarrollo individual no exista, ni tampoco que la individualidad, indígena o no indígena, no pueda desplegarse y afirmarse libremente, sino más bien que ella debe siempre tomar en cuenta a la comunidad y al nosotros, y cuidar de no anteponerse o prevalecer sobre ellos. Y si es claro que el individualismo capitalista dominante, ha llegado ya al extremo de provocar como su principal resultado la creación de una sociedad de individuos egoístas, aislados y cada vez más solitarios y enajenados por el afán competitivo y de falsa autoafirmación, entonces esta revaloración del nosotros comunitario y colectivo defendida por los pueblos indios, se presenta como una salida inteligente y cualitativa, que puede ser asumida y secundada por todo el conjunto de los movimientos antisistémicos contemporáneos.

Pues en esta revaloración indígena del 'nosotros', que postula su claro predominio sobre el 'yo', se trata de un predominio que lejos de anular o bloquear el libre desarrollo de la individualidad, le crea más bien mejores, superiores y mucho más vastas condiciones de su despliegue y de su florecimiento, a partir de la acompasada y coordinada afirmación de lo individual con lo colectivo, o de lo individual desde y dentro de lo colectivo. Lo que no casualmente, nos recuerda la aguda tesis de Marx (1974), de definir a la futura sociedad comunista como "una comunidad de individuos libres", es decir, como una nueva forma de organización social en la cual la absurda antítesis entre individuo y comunidad, o entre el "yo" y el "nosotros", ha sido ya superada, para dar paso a una nueva situación, en la cual se da el "desarrollo libre de las individualidades", pero siempre desde y dentro del marco de la comunidad, porque "solamente dentro de la comunidad es posible, por tanto, la libertad personal", y solo "dentro de la comunidad real y verdadera, los individuos adquieren al mismo tiempo su libertad, al asociarse, y por medio de la asociación”.18

Inteligente aporte de los movimientos indígenas, este del principio 'nóstrico', que nos recuerda que la transformación social radical por la que luchamos, no se

\footnotetext{
18 Sobre el papel decisivo del 'nosotros' en las comunidades indígenas, y sobre su claro predominio frente al yo individual, cfr. Carlos Lenkersdorf, Filosofar en clave tojolabal, Ed. Miguel Ángel Porrúa, México, 2002, y Carlos Antonio Aguirre Rojas, "La muerte (simbólica) del Subcomandante Insurgente Marcos y el nosotros colectivo neozapatista”, en Contrahistorias, núm. 24, México, 2015. Las agudas tesis de Marx sobre los vínculos entre individuo y comunidad, están planteadas en el capítulo 1 de $L a$ Ideología Alemana, Ed. de Cultura Popular, México, 1974, p. 87, y en los Grundrisse, o Elementos fundamentales para la crítica de la economía política. (Borrador) 1857-1858, tres tomos, Ed. Siglo XXI, México, 1971 - 1976, y en particular, tomo I, pp. 83-93, y tomo II, pp. 31-39 y 229.
} 
reduce a la conquista y expropiación de los medios sociales de producción, ni a la destrucción y abolición total del Estado en cuanto tal, sino que abarca también la complicada y sistemática reinvención y reconstrucción global de la sociedad entera, desde este principio nóstrico, comunitario, o colectivo, reconstrucción que deberá de rehacer el entero tejido social desde renovadas y complejas estructuras comunitarias, las que además, deberán estar presentes en la economía, en lo social, en lo cultural y hasta en lo civilizatorio, es decir a todo lo largo y ancho de la entera estructura social.

Un aporte más de estos movimientos indígenas latinoamericanos, es el que deriva de su particular práctica y concepción de lo que es y de lo que debe ser la democracia. Pues lejos de la limitada y empobrecida democracia capitalista hoy dominante en escala planetaria, que es en verdad una democracia falsamente representativa, y en realidad más bien delegativa, sustitutiva y suplantativa, lo que los pueblos indios de Latinoamérica practican cotidianamente y reivindican radicalmente a través de sus diversos movimientos, es la democracia directa y asamblearia, que es la única que corresponde de manera estricta al sentido etimológico del término, es decir, al verdadero 'gobierno del pueblo', el que bien entendido se convierte necesariamente en idéntico al autogobierno popular.

Pues hoy es claro que en todas las democracias capitalistas actualmente presentes a lo largo y ancho del globo terráqueo, y mediante la burda y cada vez más desacreditada trampa de las elecciones, las clases populares eligen cada cierto tiempo a aquella minoría que, bajo la mentira de 'representarlas', le expropia en realidad a la mayoría que son esas mismas clases populares y subalternas, su fundamental y esencial capacidad de decidir autogestivamente sobre sus principales asuntos colectivos. Lo que, como vemos ahora, genera la conformación de una sectaria y consolidada clase política, la que aparentando estar dividida en una fracción supuestamente 'conservadora' y otra pretendidamente 'demócrata' o 'progresista', desarrolla en realidad un claro interés unitario y cohesionador, al modo de una corporación o cofradía, para mantener y reproducir el verdadero secuestro del control y usufructo del real monopolio de la gestión y decisión de esos asuntos colectivos antes mencionados.

Frente a esto, los movimientos indígenas han reivindicado las figuras, al mismo tiempo muy viejas y muy nuevas, de las formas de la democracia asamblearia o directa, en donde las comunidades mismas deciden en Asamblea la solución de sus problemas colectivos y el destino de sus asuntos comunes, mediante mecanismos que buscan más bien el consenso que la eliminación del adversario y de las posturas distintas a la propia. Y ello, a través de modos de funcionamiento en donde los representantes realmente representan a sus comunidades y a sus representados, 
pues están regidos por mandatos imperativos, y en donde ellos, en tanto reales representantes, rinden cuentas permanentemente, siendo además elegibles, llamables a cuentas, revocables y sustituibles en cualquier momento, por parte de sus propios representados. 19

Una forma de democracia directa, que no es sólo la forma originaria y primigenia que dio lugar a la invención del concepto en la antigua Grecia, sino que también es la forma que, espontáneamente, despliegan las clases y los sectores subalternos, cada vez que mediante sus luchas y combates, tienen la ocasión de ensayar el ejercicio del gobierno, o el de la asunción y resolución de los asuntos colectivos de una determinada comunidad. Tal y como lo ilustran, claramente y en los tiempos cercanos y recientes, desde la rica experiencia de la Comuna de París, hasta las Juntas de Buen Gobierno neozapatistas, y pasando por la experiencia del gobierno de los Soviets durante los primeros años de la Revolución rusa, o la de los Consejos Obreros de Alemania, Hungría o Italia, entre otros ejemplos posibles.

Y es claro que también en este ámbito de la política, esta contribución de los movimientos indígenas de América Latina es importante, pues ella no sólo nos recuerda que no se trata de apoderarse del Estado actual y de administrarlo nosotros --como hacen por ejemplo los gobiernos progresistas de Latinoamérica--, sino que nuestro objetivo real es más bien el de destruir y hacer añicos toda forma posible de Estado, y junto a él a esa forma de la democracia suplantativa que lo acompaña y legitima, e incluso también a toda la degradada forma de la política actualmente dominante, para sustituirlos por un gobierno que genuinamente 'mande obedeciendo', apoyado en esas formas de la democracia directa y asamblearia ya mencionadas.

Finalmente, otra contribución importante de los movimientos indígenas antisistémicos de América Latina al conjunto de las luchas anticapitalistas hoy en

\footnotetext{
19 Sobre la crítica a la limitada democracia burguesa, y también a la política burguesa de la que ella forma parte, siempre es útil volver a revisar los textos clásicos, tanto de Marx, el capítulo primero de La Ideología Alemana, cit., y La guerra civil en Francia, Ed. Desde Abajo, Bogotá, 2011, como de Lenin, El Estado y la Revolución, Ed. Progreso, Moscú, sin fecha de edición. También pueden verse, Jean-Paul Sartre, "Las elecciones: una trampa para bobos", en Contrahistorias, núm. 14, 2010, Sergio Rodríguez Lascano, La crisis del poder y nosotr@s, Ed. Rebeldía, México, 2010, "La forma zapatista de hacer política. Entrevista”, en Viento Sur, núm. 83, 2005 y Carlos Antonio Aguirre Rojas, Les leçons politiques du néozapatisme mexicain. Commander en obéissant, Ed. L'Harmattan, Paris, 2010, "Noua démocratie to noilor antisistemice din America Latina miscari", (en lengua rumana: La nueva democracia de los nuevos movimientos antisistémicos de América Latina), en Stiinte Politice, vol. III, Iasi, Rumania, 2008, Immanuel Wallerstein. Crítica del sistema-mundo capitalista, Ed. LOM, Santiago de Chile, 2004, "La Otra Política de la Otra Campaña: la muerte de la política y el renacimiento del poder social", en Contrahistorias, núm. 6, 2006, "Gerando o contrapoder, de baixo para cima e à esquerda", en Lutas Sociais, núm. 17/18, Sao Paulo, 2007, y "Releyendo La guerra civil en Francia desde la América Latina del Siglo XXI", en Contrahistorias, núm. 16, México, 2011.
} 
curso en todo el planeta, es el que se refiere a su modo de concebir y de vivir la cultura, los saberes, el arte y la ciencia, modo que difiere radicalmente de la manera burguesa capitalista de asumir y percibir a estas mismas dimensiones y actividades centrales de la vida social en general. Pues mientras que para los pueblos y los movimientos indios, el arte y la ciencia son parte de la vida misma, y el saber y la cultura son realidades directamente presentes en su vida cotidiana, en cambio para la sociedad burguesa moderna el arte, la ciencia y la cultura son consideradas más bien como mercancías, y por ello, como realidades y productos sociales sometidos a la lógica del lucro, y además como actividades confinadas a pequeños y selectos grupos de personas, es decir, actividades y realidades vividas como el privilegio de unos pocos, y como elementos separados de la cotidianeidad y de la vida ordinaria de las grandes mayorías.

Por eso, para el capitalismo, el arte y las obras de arte sólo están en los Museos, en las Galerías, en los Teatros y en las Salas de Conciertos, mientras que el saber y la ciencia sólo se producen en las Universidades, en los Laboratorios y en las Instituciones científicas, siendo además obra de los llamados 'artistas' o 'científicos'. Y también para la concepción capitalista burguesa del mundo, la cultura es sólo el privilegio y patrimonio de los llamados 'intelectuales' o de los designados 'hombres de cultura', además de una forma de valorizar más la propia fuerza de trabajo mediante lo que se llama 'educación'. Lo que explica que cultura, arte y ciencia sean aquí concebidos como vulgares mercancías, como cosas que pueden comprarse y venderse, y por ende, degradarse y banalizarse como cualquier producto u objeto, aceptable o desechable a voluntad.

Frente a esta empobrecida percepción, brilla con fuerza la visión indígena de estas realidades mencionadas, en las que el arte es una creación colectiva y cotidiana, de toda la comunidad en su conjunto, y una actividad destinada a hacer la vida siempre más gozosa y más alegre, incorporando en esa vida de todos los días el baile, y la música, y los coloridos y bellos tejidos de sus telas, y sus pinturas y poesías, y sus leyendas y relatos, los que no están ni en Museos ni en Salas de Exhibición alguna, sino en su actividad y convivencia cotidianas y permanentes. Y lo mismo sucede con los saberes y las ciencias, las que no se separan de la experiencia directa, sino que nacen de ella y con ella se retroalimentan, funcionando como saberes que existen no para la especulación pura ni para el autocultivo de las personas, sino para la solución de problemas prácticos, y para el enriquecimiento humano de la comprensión inteligente del mundo. De donde deriva también que la cultura no es algo aparte de su vida social, ni patrimonio de un pequeño grupo, ni privilegio obtenido en las escuelas y Universidades, sino más bien una dimensión más, rica y compleja, de todas sus actividades y de todas sus tareas cotidianas. 
Nociones diversas y antitéticas de la concepción capitalista, sobre el arte, la cultura y la ciencia, defendidas por los movimientos indígenas, que no casualmente nos recuerdan la radical tesis de Marx (1974), luego recuperada y asumida también por Walter Benjamin (2003), sobre la muy cercana 'muerte del arte y de los artistas', la que se dará no por la extinción absoluta de la actividad artística, sino al contrario, por medio de su generalización a todos los seres humanos y mediante la reintegración de dicha actividad artística dentro de la vida social cotidiana de todas las comunidades humanas. Pues cuando todos seamos artistas, ya no habrá artistas, y cuando el arte sea solo una dimensión más de la propia vida social, ya no habrá 'arte' tal y como ahora es concebido. Una tesis que fácilmente puede extenderse también a la ciencia, y desde la cual es posible igualmente criticar la banalización y degradación burguesas del arte, de la ciencia y de la cultura, que se materializa en la conformación de lo que la Escuela de Frankfurt llamó acertadamente la moderna 'industria cultural'.20

Estos son algunos de los principales aportes que los movimientos indígenas latinoamericanos han desarrollado como su contribución específica al conjunto de los movimientos anticapitalistas y antisistémicos de todo el mundo. Los que, vistos en su conjunto, y junto a otros muchos factores, han contribuido también al proceso mediante el cual, estos movimientos antisistémicos actuales, han recuperado y potenciado su antigua radicalidad anticapitalista, para desplegar ahora, en sus distintos combates, en la configuración de sus objetivos inmediatos y mediatos, en sus nuevos métodos y formas de lucha, en sus estrategias y sus tácticas, y en sus formas de organización principales, una verdadera y profunda lógica antisistémica, que es capaz de 'impensar' el mundo actual, y de desmontar de manera crítica al

20 Sobre el tema del arte y la ciencia, resultan muy interesantes las recientes iniciativas del neozapatismo mexicano de los Festivales 'CompArte por la Humanidad' y de los Encuentros 'L@s Zapatistas y las ConCiencias', de 2016, 2017 y 2018, así como todos los Comunicados correspondientes a estos Festivales y Encuentros, del Subcomandante Insurgente Moisés y del Subcomandante Insurgente Galeano, consultables en el sitio de Enlace Zapatista: http://www.ezln.org.mx. También puede verse, W. Benjamin, La obra de arte en la época de su reproductibilidad técnica, Ed. Itaca, México, 2003, y Carlos Antonio Aguirre Rojas, "Arti, scienze e saperi neozapatisti. Far nascere dal basso il nuovo mondo non capitalista", en el libro EZLN $e$ movimenti dal basso, Ed. Elementi Kairós, Roma, 2017. Y sobre el complejo tema de la cultura, cfr. Bolívar Echeverría, Definición de la Cultura, Ed. Fondo de Cultura Económica, México, 2010, Carlo Ginzburg, El queso y los gusanos, Ed. Muchnik, Barcelona, 1991, Mijail Bajtin, La cultura popular en la Edad Media y en el Renacimiento. El contexto de François Rabelais, Ed. Alianza Editorial, Madrid, 1987, Edward P. Thompson, Costumbres en común, Ed. Crítica, Barcelona, 1995, y Carlos Antonio Aguirre Rojas, "Hegemonic cultures and Subaltern cultures: Between Dialogue and Conflict", en Review, vol. XXVIII, núm. 2, 2005. 
pensamiento burgués dominante, para enseñarnos a observar y a explicar la realidad, 'desde abajo y a la izquierda'. 21

Aportes importantes que enriquecen a los movimientos anticapitalistas de todo el planeta, y que además de complejizar y hacer más aguda y penetrante la crítica actual del capitalismo mundial, nos acercan también un poco más, en los hechos inmediatos y en las expectativas futuras actuales, al igualmente complejo proceso de la construcción en curso de un mundo no capitalista, donde no existen ya relaciones de explotación económica, ni la desigualdad social en sus múltiples formas, y en donde han sido ya abolidos las clases sociales, la propiedad privada, el Estado, y todas las absurdas e injustificadas jerarquías sociales, políticas y culturales de todo orden, trascendiendo además las distintas formas de discriminación social antes existentes, para ceder su lugar a nuevas relaciones fraternas, de igualdad y de convivencia, entre los distintos seres humanos.

\section{Bibliografía}

Aguirre Rojas, C. (1996): "A longa duraçao: in illo tempore et nunc", Revista de Historia Das Ideias, 18.

Aguirre Rojas, C. (2002): "Lateinamerika heute: Eine Darstellung aus der Sicht den 'langen Dauer', Comparativ, 12(5/6).

Aguirre Rojas, C. (2003): "A história da civilizaçao latino-americana ", en VV.AA., Fernand Braudel. Tempo e história. Rio de Janeiro, Ed. FGV Editora

Aguirre Rojas, C. (2004a): América Latina. História e Presente. Sao Paulo, Ed. Papirus.

Aguirre Rojas, C. (2004b): Immanuel Wallerstein. Crítica del sistema-mundo capitalista. Santiago de Chile, Ed. LOM.

21 Sobre esta lógica antisistémica y crítica, cfr. el libro de la Comisión Sexta del EZLN, El pensamiento crítico frente a la hidra capitalista I, Ed. EZLN, México, 2015, y los siguientes textos incluidos en el número 25 de Contrahistorias: Michel Foucault, “¿Qué es la crítica? Crítica y Aufklärung”, Bolívar Echeverría, "Definición del discurso crítico", Carlo Ginzburg, "Extrañamiento. Prehistoria de un procedimiento literario". También pueden verse, Carlos Antonio Aguirre Rojas, "La contribution du néozapatisme mexicain au développement de la pensée critique contemporaine", en revista Theomai, núm. 35, 2017, y "A Mirada neozapatista: olhar (para e desde) baixo e à esquerda", en História e Luta de Classes, año 7, núm. 11, Paraná, 2011. 
Aguirre Rojas, C. (2004c): Fernand Braudel et les sciences humaines. París, Ed. L'Harmattan.

Aguirre Rojas, C. (2005a): América Latina: Crisis Global y Cultura Plural. Shen Zhen, Ed. Universidad de Shen Zhen.

Aguirre Rojas, C. (2005b): "Bolivia rebelde. Las lecciones de los sucesos de mayo y junio de 2005, en perspectiva histórica", Contrahistorias, 5.

Aguirre Rojas, C. (2005c): "Hegemonic cultures and Subaltern cultures: Between Dialogue and Conflict", Review, 28(2).

Aguirre Rojas, C. (2006): "La Otra Política de la Otra Campaña: la muerte de la política y el renacimiento del poder social", Contrahistorias, 6 .

Aguirre Rojas, C. (2007a): "Gerando o contrapoder, de baixo para cima e à esquerda", Lutas Sociais, 17/18.

Aguirre Rojas, C. (2007b): “'Globalization' and 'Mondialization': A Critical Historical Perspective", Stiinte Politice, 2.

Aguirre Rojas, C. (2008a): L’Amérique Latine en rébellion. París, Ed. L'Harmattan,

Aguirre Rojas, C. (2008b): "Les nouveaux mouvements antisystemiques en Amérique Latine: une brève radiographie générale", Review, 31(1).

Aguirre Rojas, C. (2008c): "Noua démocratie to noilor antisistemice din America Latina miscari", Stiinte Politice, 3.

Aguirre Rojas, C. (2010a): Chiapas, Planeta Tierra, Ed. Contrahistorias, México, 2010,

Aguirre Rojas, C. (2010b): "Latin America's Antisystemic Movements and its Struggle for the Land in the Twenty-First Century", Review, 32(4).

Aguirre Rojas, C. (2010c): Les leçons politiques du néozapatisme mexicain. Commander en obéissant. Paris, Ed. L’Harmattan.

Aguirre Rojas, C. (2010d): Para compreender o século XXI. Uma gramática de longa duração. Porto Alegre, Ed. Universidade de Passo Fundo - Editora da Pontificia Universidade Catolica de Rio Grande do Sul. 
Aguirre Rojas, C. (2011a): "A Mirada neozapatista: olhar (para e desde) baixo e à esquerda”, História e Luta de Classes, 7(11).

Aguirre Rojas, C. (2011b): "Releyendo La guerra civil en Francia desde la América Latina del Siglo XXI", Contrahistorias, 16.

Aguirre Rojas, C. (2013a): Gehorchend befehlen. Die politischen Lektionen des mexikanischen Neozapatismus. Münster, Ed. Assemblage.

Aguirre Rojas, C. (2013b): Movimenti Antisistemici. Pensare un'alternativa nel XXI secolo. Roma, Ed. Aracne Editrice.

Aguirre Rojas, C. (2013c): "O que são os movimentos antisistêmicos?", História em reflexão, 7(13). Disponible en http://www.periodicos.ufgd.edu.br/index.php/historiaemreflexao

Aguirre Rojas, C. (2014): "El significado del neozapatismo mexicano dentro de los movimientos antisistémicos actuales”, Contrahistorias, 22.

Aguirre Rojas, C. (2015a): Antimanuale del buon ribelle. Roma, Ed. Aracne Editrice.

Aguirre Rojas, C. (2015b): "La muerte (simbólica) del Subcomandante Insurgente Marcos y el nosotros colectivo neozapatista”, Contrahistorias, 24.

Aguirre Rojas, C. (2017a): "Arti, scienze e saperi neozapatisti. Far nascere dal basso il nuovo mondo non capitalista", en VV.AA., EZLN e movimenti dal basso. Roma Ed. Elementi Kairós.

Aguirre Rojas, C. (2017b): "La contribution du néozapatisme mexicain au développement de la pensée critique contemporaine", Theomai, 35.

Aguirre Rojas, C. (2018): Movimientos Antisistémicos y Cuestión Indígena en América Latina. Una visión desde la larga duración histórica. Santiago de Chile, Ed. Quimantú.

Aguirre Rojas, C. (2019): La tierna furia. Nuevos ensayos sobre el neozapatismo mexicano. México, Ed. Contrahistorias.

Anderson, B. (1993): Comunidades imaginadas. Reflexiones sobre el origen y la difusión del nacionalismo. México, Ed. Fondo de Cultura Económica. 
Asamblea Constituyente de Bolivia (2009): Constitución Política del Estado Plurinacional de Bolivia (2009). Disponible en web: www.asambleanacional.gov.ec/documentos/constitucion_de_bolsillo.pdf

Asamblea Constituyente de Ecuador de 2007 y 2008 (2008): Constitución de la República del Ecuador (2008). Disponible en web: https://bolivia.infoleyes.com/norma/469/constitución-política-del-estado-cpe

Bajtin, M. (1987): La cultura popular en la Edad Media y en el Renacimiento. El contexto de François Rabelais. Madrid, Ed. Alianza Editorial.

Benjamin, W. (2003): La obra de arte en la época de su reproductibilidad técnica. México, Ed. Itaca.

Braudel, F. (1984): Civilización material, economía y capitalismo. Siglos XV-XVIII. Madrid, Alianza Editorial

Braudel, F. (1991): Escritos sobre historia. México, Ed. Fondo de Cultura Económica.

Braudel, F. (2010): El Mediterráneo y el mundo mediterráneo en la época de Felipe II. México, Ed. Fondo de Cultura Económica.

Comisión Sexta del EZLN (2015): El pensamiento crítico frente a la hidra capitalista I. México, Ed. EZLN.

CONAIE (s/f): Boletines Confederación de Nacionalidades Indígenas del Ecuador. Disponible en web: https://www.conaie.org

Coordinadora Arauco Malleco (2015): "El pensamiento emancipatorio de la Coordinadora de Comunidades Mapuche en Conflicto (CAM)", Contrahistorias, 25.

Echeverría, B. (1995): "Modernidad y Capitalismo (15 tesis)", en VV.AA., Las ilusiones de la modernidad. México, Coedición Ed. UNAM - Ed. El Equilibrista.

Echeverría, B. (1998): La modernidad de lo barroco. México, Ed. Era.

Echeverría, B. (2010): Definición de la Cultura. México, Ed. Fondo de Cultura Económica. 
Echeverría, B. (2011): "El Socialismo del Siglo XXI es un Capitalismo Cristiano Corregido", Contrahistorias, 16.

Echeverría, B. (2015): “Definición del discurso crítico”, Contrahistorias, 25.

Eliade, M. (2004): Tratado de Historia de las Religiones. México, Ed. Era.

Elías, N. (1989): El proceso de la civilización. México, Ed. Fondo de Cultura Económica.

Elías, N. (1990): Compromiso y distanciamiento. Barcelona, Ed. Península.

Elías, N. (2016): Establecidos y marginales. México, Ed. Fondo de Cultura Económica.

Foucault, M. (2006): Seguridad, Territorio, Población. Buenos Aires, Ed. Fondo de Cultura Económica.

Foucault, M. (2015): “¿Qué es la crítica? Crítica y Aufklärung”, Contrahistorias, 25.

Giménez Heau, J. (2001): "El ISBG: laboratorio global o negocio redondo", Chiapas, 12.

Ginzburg, C. (1991): El queso y los gusanos. Barcelona, Ed. Muchnik.

Ginzburg, C. (2015): "Extrañamiento. Prehistoria de un procedimiento literario", Contrahistorias, 25.

Gómez, L. (2006): El Alto de Pie. Una insurrección aymara en Bolivia. La Paz, Ed. Imprenta Wa-Gui.

Hobsbawm, E. (1991): Naciones y nacionalismo desde 1780. Barcelona, Ed. Crítica.

Lenkersdorf, C. (2002): Filosofar en clave tojolabal. México, Ed. Miguel Ángel Porrúa.

Lenin, V. (s/f): El Estado y la Revolución. Moscú, Ed. Progreso.

Marx, C. (1971 - 1976): Grundrisse: Elementos fundamentales para la crítica de la economía política. (Borrador) 1857-1858, tres tomos. México, Ed. Siglo XXI.

Marx, C. (1974): La Ideología Alemana. México, Ed. de Cultura Popular. 
Marx, C. y F. Engels (1973): Manifiesto del Partido Comunista, Pekín, Ed. en Lenguas Extranjeras.

Marx, C. (2011): La guerra civil en Francia. Bogotá, Ed. Desde Abajo.

Olivera, O. et al (2008): Nosotros somos la Coordinadora. La Paz, Ed. Fundación Abril.

Olivera, 0. et al (2011): "Carta Pública Abierta a Evo Morales y a Álvaro García, contra el Gasolinazo y por el Autogobierno de nuestro pueblo”, Contrahistorias, 16.

Pairicán, F. (2014): Malon. La rebelión del movimiento mapuche 1990 - 2013. Santiago de Chile, Ed. Pehuén Editores.

Quispe, F. (2013): La caída de Goni. Ed. Pachakuti, La Paz, 2013,

Quispe, F. (2016): “Entrevista sobre la situación actual de Bolivia (23 de junio de 2015)", Contrahistorias, 26.

Rodríguez Lascano, S. (2005): "La forma zapatista de hacer política. Entrevista", Viento Sur, 83.

Rodríguez Lascano, S. (2010): La crisis del poder y nosotr@s. México, Ed. Rebeldía.

Santi, M. (2008): "Un nuevo giro hacia la izquierda. La Confederación de Nacionalidades Indígenas del Ecuador. Entrevista”, Contrahistorias, 11.

Sartre, J. P. (2010): “Las elecciones: una trampa para bobos”, Contrahistorias, 14.

Subcomandante Insurgente Marcos (2006): "El elemento extra: la organización", Rebeldía, 42.

Subcomandante Insurgente Marcos (2007) "De redentores e irredentos", discurso del 16 de julio de 2007. Disponible en web 'Enlace Zapatista': http://www.ezln.org.mx

Subcomandante Insurgente Marcos (2017): "Siete piezas sueltas del rompecabezas mundial", en Subcomandante Insurgente Marcos, Escritos sobre la guerra y la economía política. México, Ed. Pensamiento Crítico Ediciones. 
Subcomandante Insurgente Moisés (2015a): "Economía Política I. Una mirada desde las comunidades zapatistas", en El pensamiento crítico frente a la hidra capitalista I. Participación de la Comisión Sexta del EZLN. México, Ed. EZLN.

Subcomandante Insurgente Moisés (2015b): “Economía Política II. Una mirada desde las comunidades zapatistas", en El pensamiento crítico frente a la hidra capitalista I. Participación de la Comisión Sexta del EZLN. México, Ed. EZLN.

Thompson, E. P. (1995): Costumbres en común. Barcelona, Ed. Crítica.

Toledo Ocampo, A. (1998): "Hacia una economía política de la biodiversidad y de los movimientos ecológicos comunitarios”, Chiapas, 6.

Valdés Castillo, M. (2016): “Tres décadas de cuantificación de la población indígena en Chile a través de los Censos", Notas de Población, 43(103).

VV.AA. (1992): Indios. Una reflexión sobre el levantamiento indígena de 1990. Quito, Ed. Abya Yala.

VV.AA. (2001): Yuyarinakuy. Digamos lo que somos, antes que otros nos den diciendo lo que no somos. Quito, Ed. Abya Yala.

VV.AA. (2004): ¿A dónde vamos?. Progreso en diferentes culturas. La Paz, Ed. Fundación PIEB.

VV.AA. (2005): Autonomía Indígena frente al Estado nación y la globalización neoliberal. Quito, Ed. Abya Yala.

VV.AA. (2012): La victoria indígena del TIPNIS. La Paz, Ed. Imprenta WA-GUI.

Wallerstein, I. (1996): Después del liberalismo. México, Ed. Siglo XXI.

Wallerstein, I. G. Arrighi y T. Hopkins (1999): Movimientos Antisistémicos. Madrid, Ed. Akal.

Wallerstein, I. (2003): "Las nuevas rebeliones antisistémicas: ¿un movimiento de movimientos?", Contrahistorias, 1.

Wallerstein, I. y E. Balibar (2005): Race, Nation, Class. Ambiguous Identities. Londres y Nueva York, Ed. Verso. 
Wallerstein, I. (2008): Historia y dilemas de los movimientos antisistémicos. México, Ed. Contrahistorias.

Wallerstein, I. (2011- 2014): I. El moderno sistema mundial, tomos I, II, III, y IV. México, Ed. Siglo XXI.

Wallerstein, I., C. Lemert y C. Aguirre Rojas (2012): Uncertain Worlds. WorldSystems Analysis in Changing Times. Bouldon, Ed. Paradigm Publishers.

Wallerstein, I. (2015a): "Entrevista sobre los nuevos movimientos antisistémicos en México y en el mundo (enero de 2015)", Contrahistorias, 24.

Wallerstein, I. (2015b): Horizontes del análisis del sistema-mundo moderno. México, Ed. Instituto Politécnico Nacional.

Wallerstein, I. (2016): La crisis estructural del capitalismo. Santiago de Chile, Ed. Quimantú.

Zibechi, R. (2008a): Autonomías y emancipaciones. América Latina en movimiento. Santiago de Chile, Ed. Quimantú.

Zibechi, R. (2008b): Dibujando fuera de los márgenes. Los movimientos sociales en América Latina. Entrevista. Buenos Aires, Ed. La Crujía Ediciones.

Zibechi, R. (2016): “Crítica de los gobiernos 'progresistas”, Contrahistorias, 26.

Zibechi, R. y D. Machado (2016): Cambiar el mundo desde arriba. Los límites del progresismo. Bogotá, Ed. Desde Abajo.

Zibechi, R. (2017): Movimientos Sociales en América Latina. El 'mundo otro' en movimiento. Bogotá, Ed. Desde Abajo. 